\title{
INVESTIGATION OF PHASE AND EMULSION BEHAVIOR, SURFACTANT RETENTION, AND CONDENSATE RECOVERY FOR CONDENSATE/WATER/ETHANOL MIXTURES
}

FINAL REPORT

REPORTING PERIOD START DATE：OCTOBER 01, 2002

REPORTING PERIOD END DATE： SEPTEMBER 30, 2005

PRINCIPAL AUTHOR:

RAMANATHAN SAMPATH, PH.D

DATE REPORT WAS ISSUED: DECEMBER, 2005

GRANT NUMBER: $\quad$ DE-FG26-02NT15447

NAME AND ADDRESS OF SUBMITTING ORGANIZATION: DEPARTMENT OF PHYSICS AND DUAL DEGREE IN ENGINEERING MOREHOUSE COLLEGE

ATLANTA, GA 30314 


\section{DISCLAIMER}

This report was prepared as an account of work sponsored by an agency of the United States Government. Neither the United States Government nor any agency thereof, nor any of their employees, makes any warranty, express or implied, or assumes any legal liability or responsibility for the accuracy, completeness, or usefulness of any information, apparatus, product, or process disclosed, or represents that its use would not fringe privately owned rights. Reference herein to any specific commercial product, process, or service by trade name, trademark, manufacturers, or otherwise does not necessarily constitute or imply its endorsement, recommendation, or favoring by the United States Government or any agency thereof. The views and opinions of authors expressed herein do not necessarily state or reflect those of the United States Government or any agency thereof. 
Investigation of Phase and Emulsion Behavior, Surfactant Retention, and Condensate Recovery for Condensate/Water/Ethanol Mixtures

\begin{abstract}
This final technical report describes work performed at Morehouse College under DOE Grant No. DE-FG26-02NT15447 during the period October 01, 2002 to September 30, 2005, which covers the total performance period of the project. During this period, work was conducted to characterize phase and emulsion behavior for ethylbenzene/water/ethanol system. Ethylbenzene that has the equivalent carbon number was used as the model condensate. Salinity scans were performed for 0 , $5,10,20,50,100,250,500$, and $1000 \mathrm{mM}$ salt concentrations at room temperature to identify the optimal salinity and salinity intervals in which all phases coexisted. It was found that only two phases formed, and salinity has no significant effect in the volumes of the phases formed. Experiments were repeated at $30^{\circ} \mathrm{C}$ and observed salinity has no effect at higher temperatures as well. Following the salinity experiments, measurements were made with $10 \mathrm{mM} \mathrm{NaCl}$ water for surfactant concentrations from 2 to 70 volume percent at room temperature. It was found that only two phases were formed upto $60 \mathrm{vol} \%$ concentration of the surfactant. Above $60 \mathrm{vol} \%$ surfactant, the mixture produced only a single phase. Experiments were repeated from 2 to $70^{\circ} \mathrm{C}$ and observed that temperature has no significant effect on the number of phases formed. At the temperatures and surfactant concentration tested, volume fraction of the aqueous bottom phase was found to be larger than that of the top phase. Electrical conductivity measurements were then conducted for bottom/top, and top/bottom conjugate pair phases of the ethylbenzene/water/ethanol system formed by mixing ethanol at various volume percentages including 2,10,33, and 56\% while keeping the volumes of ethylbenzene and water the same in the mixture. Electrical conductivity of the bottom phase decreased as ethanol volume fraction in the mixture increased. Conductivity of the top phase was found small and remained almost the same for variations in ethanol volume fraction in the mixture. Also inversion phenomena was observed. Prediction of the conductivity data obtained was then conducted employing a theoretical model developed in this project based on Maxwell relations. Results of the comparisons for 2, 10,33, and 56\% ethanol volume in the mixture are presented here. A good agreement was obtained between the predicted emulsion conductivities and the measured values. Work was also conducted at Surtek, Golden, CO, our industrial partner in this project, to measure the effectiveness for condensate recovery employing coreflooding techniques. In Run 1 of the radial coreflooding experiments conducted, $10 \mathrm{mM} \mathrm{NaCl}$ without ethanol injection recovered $31.5 \%$ of the initial ethyl benzene saturation. Injection of ethanol following $10 \mathrm{mM} \mathrm{NaCl}$ produced a tertiary ethyl benzene bank with maximum ethyl benzene cuts of $32 \%$. In Run $2,50 \mathrm{vol} \%$ of pure $(100 \%)$ ethanol was injected and flowed through the Berea sandstone after Ethyl Benzene Saturation. $69 \%$ of the initial ethyl benzene was recovered. While $50 \mathrm{vol} \%$ of ethanol injection does not make economic sense when injecting a large fraction of a pore volume, injection of sufficient volume to remove water and condensate from around the near well bore area of a gas well could be economic.
\end{abstract}


TABLE OF CONTENTS

page

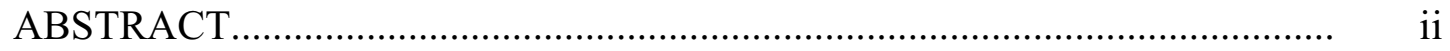

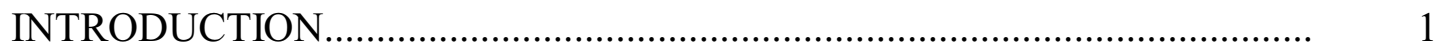

EXECUTIVE SUMMARY ……………………………………………..

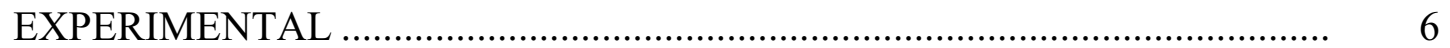

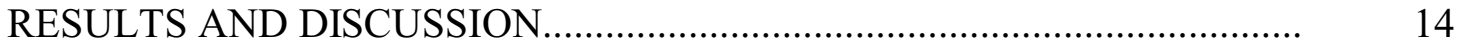

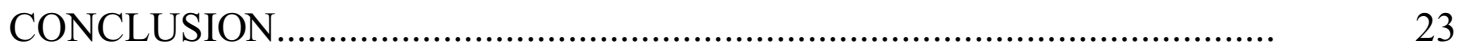

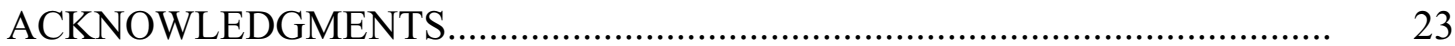

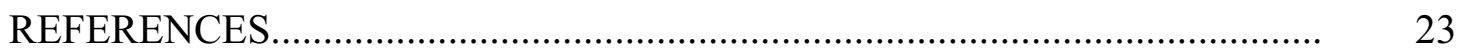




\section{INTRODUCTION}

The Department of Energy has been sponsoring fundamental and applied research in the natural gas recovery area. Recently, NETL-Tulsa has been interested in research focusing on innovative methods for technologies towards improved gas and condensate recovery. If an effective method can be found, the potential for incremental recovery is great.

The major factors causing hydrocarbon losses in a reservoir during production of gas and gas condensate fields are related to pressure depletion, retrograde condensation, and water encroachment. The most widespread and simple method of producing gas and gas condensate fields is by depletion, utilizing the natural reservoir pressure only. The major disadvantage of the method is the low condensate recovery. The ultimate condensate recovery from gas condensate fields is $30-60 \%$, depending on the initial content of condensate in gas. In comparison, the final recovery of gas in dry gas fields can be up to $95 \%$. Despite the low recovery of condensate associated with natural depletion, this method is still widely used in the majority of gas condensate fields in the world. The reasons for this are both technological and economical. Achieving increased production in partially depleted gas and gas condensate fields is essential for many gas producing companies. Incremental production can be very profitable especially in industrially developed countries. Worldwide, the potential for production and improved recovery from gas condensate fields is considerable. In order to improve the recovery from gas condensate fields innovative methods are required.

Depletion of reservoir pressure leads to a reduction in flow capacity and normally causes retrograde condensation. Offsetting the reduced flow capacity by lowering the bottom hole flowing pressure can result in near wellbore retrograde condensation, which leads to decreased effective permeability and additional reduction of flow rates. Lower production rates leads to earlier abandonment resulting in lower ultimate recovery. Significant amounts of condensate can accumulate in the near wellbore zone due to the large pressure drop in this zone. This condensation takes place in addition to the condensation within the reservoir caused by the general pressure depletion. As a result of this condensate accumulation, liquid saturations in the near wellbore zone can considerably exceed the average value over the reservoir as a whole. This causes a large reduction in well productivity. The reduction of well productivity caused by near wellbore accumulation of retrograde condensate has been observed at many fields in the USA, Russia, and Canada. At these fields, the well productivity decrease reached $50 \%$ in some productive intervals due to condensate accumulation. Further pressure reduction, down to the pressure of maximum condensation, results in increased volume of condensed liquid. Then the mixture enters a range of direct evaporation and will result in further decrease of pressure. Pressure depletion below the dew-point pressure causes retrograde condensation throughout the entire system that leads to greater than $50 \%$ reduction in well productivity.

Water encroachment into a gas or gas condensate reservoir has two opposite effects: 1) maintenance of reservoir pressure, and 2) trapping gas and condensate behind the water level at higher pressure than by depletion and thus reducing the recoverable reserves. Selective water encroachment in a reservoir and breakthrough of water to production wells result in an accumulation 
of water in wells and their premature shut-in at higher formation pressures. The impact of each of the above mentioned factors on production and ultimate recovery of condensate and gas varies from reservoir to reservoir, but water encroachment is observed at all gas condensate fields to a certain degree. Application of surfactant flooding technology that is used in the Enhanced Oil Recovery technology may hold great potential for the improved recovery of condensate from the water encroached gas and condensate fields. For this, a research project aimed at understanding the emulsions formed by water, condensate, and a cosurfactant, such as ethanol, would provide valuable information including how to reduce the interfacial tension between encroaching water and condensate, and under what conditions and how this can be used towards improved recovery. The use of ethanol as the surfactant in this project would also provide valuable information on how to remove the condensate from near the wellbore by reducing the interfacial tension between the gas and condensate and hence improve the gas flow from condensate accumulated wellbores.

Application of surfactants and hence formation of emulsions depend on the desired morphology, for example, a "condensate -in-water" or a "water-in-condensate" emulsion. Formation of the "wrong" morphology or inversion from the desired morphology to the "wrong" morphology causes the product or process to fail. Mixtures of water, condensates, amphiphiles, and salt may separate into three coexisting liquid phases within a well defined temperature interval, the mean temperature of which depends sensitively but systematically on the nature of the condensate and the amphiphile and on the salt concentration. At the mean temperature of this interval one finds--for thermodynamic reasons--a maximum of the mutual solubility between water and condensate and a minimum of the interfacial tension between the aqueous and the condensate-rich phase. Both of these properties are of considerable interest for both research and industrial application.

Many, if not most, of the two-phase emulsions that may commonly exist at various temperatures in systems of surfactant, condensate, and water form in systems that also can form [1] triconjugate condensate-rich top phase (T), water-rich bottom phase (B), and middle-phase microemulsion (M). For such systems, two-phase emulsions may form in any of the various twophase regions [2-3] that surround a stack of tie triangles in the triangular-prismatic phase diagram. For temperatures between Tlc and Tuc--the range over which phases T, M, and B coexist--there are three two-phase regions and thus six nonmultiple, two phase emulsion morphologies [4]. For such systems the plotting of phase boundaries and of boundaries between different emulsion morphologies in accordance with the phase rule introduces a rigorous way of showing how the occurrence of each of the six two-phase morphologies depends on temperature and composition. For the limiting tie lines (i.e., the sides of the tie triangle), where the three-phase and two-phase regions meet, the six two-phase morphologies will be formed by the triconjugate phases taken pairwise: $\mathrm{T} / \mathrm{M}, \mathrm{M} / \mathrm{T}$; $\mathrm{B} / \mathrm{T}$, $\mathrm{T} / \mathrm{B}$; and $\mathrm{M} / \mathrm{B}, \mathrm{B} / \mathrm{M}[5]$.

One of the most widely observed phenomena of emulsion inversion is inversion hysteresis [6]. For example, the phase volume fractions at which the inversions $\mathrm{A} / \mathrm{B}$ to $\mathrm{B} / \mathrm{A}$ and $\mathrm{B} / \mathrm{A}$ to $\mathrm{A} / \mathrm{B}$ occur are somewhat different. If the pair of phase volume fraction points at which the pair of conjugate inversions occur are measured at different temperatures, the resulting measurements form a pair of inversion hysteresis lines in phase volume fraction-temperature space. The fractional phase 
volume at which inversion occurs is believed to depend on many different factors, such as the temperature, structure, and concentration of the emulsifying amphiphile, salinity, and hydrocarbon composition. The factors that control dispersion morphology and inversion are now well understood [5]. Qualitatively, dispersion inversion has long seemed to be a catastrophic event. The properties of an $\mathrm{A} / \mathrm{B}(\mathrm{A}-\mathrm{in}-\mathrm{B})$ dispersion are very different from the properties of a $\mathrm{B} / \mathrm{A}$ (B-in- $\mathrm{A})$ dispersion, and the inversion from one morphology to the other is often abrupt and irreversible. Inversion is marked by a sudden change in the physical properties (e.g., electrical conductivity) of the dispersion, indicating an abrupt change in the structure of the dispersion [5]. Smith et al. [5,7-10] demonstrated for several oil/water/surfactant systems that elementary catastrophe theory provides a unifying framework to explain these phenomena in systems of variable oil/water ratio and amphiphile concentration at constant temperature and pressure. Smith et al. [1] hypothesized that wherever a phase critical point occurs, there will be a "critical point" for dispersion inversion, also; that is, pairs of dispersion inversion hysteresis lines meet at a point, and this point coincides with the critical point for the two phases of the dispersion.

Sampath et al. [5] determined the morphologies and phase volume fractions at which inversion occurred for (macro)emulsions formed by the middle-phase microemulsion (M) and waterrich bottom phase (B) by means of electrical conductivity measurements for the chemical system $\mathrm{C} 6 \mathrm{H} 13(\mathrm{OC} 2 \mathrm{H} 4) 2 \mathrm{OH} / \mathrm{n}$-tetradecane/aqueous $10 \mathrm{mM} \mathrm{NaCl}$ at temperatures from $25^{\circ} \mathrm{C}$ down to 12 ${ }^{\circ} \mathrm{C}$, near the lower critical end-point temperature $\left(\mathrm{Tlc}=10.4{ }^{\circ} \mathrm{C}\right)$. The $\mathrm{M} / \mathrm{B}$ and $\mathrm{B} / \mathrm{M}$ morphologies and their inversion hysteresis lines were found to conform to the previously postulated dispersion morphology diagram; that is, within experimental uncertainties, the two emulsion inversion lines in phase volume-temperature space met at a "critical point"' that coincided with the lower critical end point for the phases.

The phase behavior, interfacial tension and solution physical parameters only define a single interface in the condensate recovery process, the water-condensate interface. In a condensate and water filled reservoir system, two other interfaces exist, the condensate-rock and water-rock interface. The effect of these two interfaces on the condensate recovery process are just as important, if not more important, than the water-condensate interface [11-14]. Linear and radial corefloods are used to test the effect of the two rock interfaces on the condensate recovery potential of the surfactant systems. Linear corefloods provide adsorption coefficients of chemical onto the rock surface and define fluid rheology as the ability of the solution to flow through porous media. Radial corefloods to estimate condensate recovery potential are preferable to linear corefloods for a number of reasons [11-16]. The pore volume of a radial core is greater than that of a linear core making measurement of the injected and produced fluids volumes more accurate. The flow patterns in a radial core allow expansion of the interface between the injected surfactant and the fluid in the core to occur in a similar manner as in a vertical well in the field. When fractional pore volumes of chemical are injected, chemical banks thin in a manner analogous to a vertical well in the field allowing dispersion, dilution, and other potentially deleterious effects to occur. Recently, Moeti, Sampath, Smith, and Pitts [17-19] investigated the suitability of hybrid (ionic and nonionic) surfactants for enhanced oil recovery and observed inversion hystereses but lower surfactant and hydrocarbon recovery for these surfactants. 
To this end, applying our experimental and modeling capabilities in the emulsion research [5,17-19], this project sought to characterize the phase and morphology behavior of ethylbenzene that has the equivalent carbon number of condensate when mixed with water and a cosurfactant such as ethanol and develop a database for use in improved condensate recovery from water encroached wells. Detailed information on optimal salinity, temperature, emulsion morphologies including inversion hystereses, upper critical points, and recovery efficiency were obtained for ready use in actual field operations. The information obtained will also be useful in evaluating the use of ethanol as the surfactant to remove the condensate from near the wellbore to improve the gas flow in condensate accumulated wellbores.

The specific objectives were:

1) Perform salinity and temperature scans to obtain optimal salinity and temperature at which all phases coexist.

2) Perform emulsion morphology and coreflooding experiments for the ethylbenzene/water/ethanol system that gives the best results in objective 1 .

Experiments and analyses were carried out to meet the project objectives. Morehouse accomplished salinity and temperature scans of objective 1 . Morehouse also accomplished emulsion morphology experiments, and prediction of the emulsion data of objective 2. Surtek, our industrial partner completed the coreflooding experiments. The successful accomplishment of the objectives provides a detailed database for use in improved condensate recovery from water encroached wells. 


\section{EXECUTIVE SUMMARY}

In this final technical report, the work performed under DOE Grant No. DE-FG26-02NT15447 during the period October 01, 2002 to September 30, 2005, which covers the entire performance period of the project is described and major accomplishments are highlighted, summarizing the most important research results.

Many surfactants will simultaneously form multiple coexisting liquid phases when mixed with condensate and water within a well defined salinity and temperature interval. At the mean temperature of this interval one finds--for thermodynamic reasons--a maximum of the mutual solubility between water and condensate. In a three phase mixture, the middle phase, which contains the greatest concentration of surfactant, is called a microemulsion. Typically the microemulsion reduces the interfacial tension between hydrocarbon and water by about three or four orders of magnitude. These ultralow tensions allow the hydrocarbon-rich (top) phase to be pushed through porous media by the aqueous (bottom) phase, and the three liquid phases flow as macroemulsions. The microemulsion phase can also form two-phase or three-phase macroemulsion structures or morphologies when mixed with either one or both of the other two phases, depending on the temperature, relative volumes of the phases, and other factors. Formation of a wrong morphology or inversion from the desired morphology to the wrong morphology is also possible. Investigation of these morphologies, when they occur, and their flow through porous media are of considerable interest for both research and industrial application.

This project sought to characterize phase and emulsion behavior, and condensate recovery for condensate/water/ethanol systems. Ethylbenzene that has the equivalent carbon number was used as the model condensate. Salinity scans were performed for various salt concentrations to identify the optimal salinity and salinity intervals in which all phases coexisted. It was found that only two phases formed, and salinity has no significant effect in the volumes of the phases formed. Following the salinity experiments, measurements were made with $10 \mathrm{mM} \mathrm{NaCl}$ water for surfactant concentrations from 2 to 70 volume percent at room temperature. It was found that only two phases were formed upto $60 \mathrm{vol} \%$ concentration of the surfactant, and above $60 \mathrm{vol} \%$ of surfactant produced only a single phase. Electrical conductivity measurements were then conducted for bottom/top, and top/bottom conjugate pair phases of the ethylbenzene/water/ethanol system formed by mixing ethanol at various volume percentage while keeping the volumes of ethylbenzene and water the same in the mixture. Electrical conductivity of the bottom phase decreased as ethanol volume fraction of the mixture increased. Conductivity of the top phase was found small and remained almost the same for variations in ethanol volume fraction in the mixture. Also inversion phenomena was observed. Prediction of the conductivity data obtained was then conducted employing a theoretical model developed in this project based on Maxwell relations. A good agreement was obtained between the predicted emulsion conductivities and the measured values. Work was also conducted at Surtek, Golden, CO, our industrial partner in this project, to measure the effectiveness for condensate recovery employing radial coreflooding technique. $50 \mathrm{vol} \%$ of pure $(100 \%)$ ethanol was injected and flowed through the Berea sandstone after Ethyl Benzene Saturation. Only two phases were produced and $69 \%$ of the initial ethyl benzene was recovered. 


\section{EXPERIMENTAL METHODS}

In this study detailed information on optimal salinity, temperature, emulsion morphologies, effectiveness for hydrocarbon recovery was obtained for ethylbenzene/water/ethanol system. Measurements for optimal salinity, temperature, emulsion morphologies were accomplished by Morehouse. Coreflooding experiments were completed by Surtek, our industrial partner in this project.

\section{Morehouse Measurements}

Work was conducted to characterize phase and emulsion behavior for condensate/water/ethanol system. Ethylbenzene that has the equivalent carbon number was used as the model condensate.

Salinity scans were performed to identify the optimal salinity and salinity intervals in which all phases coexisted. For this, equal volume of ethylbenzene and water with $10 \mathrm{vol} \%$ ethanol was mixed with various concentrations of $\mathrm{NaCl}(0,5,10,20,50,100,250,500$, and $1000 \mathrm{mM})$ at room temperature. Each test mixture was kept in a graduated glass bottle with the lid on this time to avoid evaporation of the mixture into the atmosphere. It was found that only two phases formed, and salinity has no significant effect in the volumes of the phases formed. Experiments were repeated at $30^{\circ} \mathrm{C}$ and observed salinity has no effect at higher temperatures as well.

Temperature scans were performed with $10 \mathrm{~mm} \mathrm{NaCl}$ in water for various surfactant concentrations ranging from 2 to $70 \mathrm{vol} \%$ in tightly closed graduated glass bottles. Experiments were repeated for a range of temperatures from 2 to $70^{\circ} \mathrm{C}$.

The small salt concentration was used to improve the sensitivity and accuracy of the conductivity measurements conducted in this project by increasing the conductivity differences between the conjugate phases of the emulsions. The best ethylbenzene/water/ethanol system defined by the above phase work was then studied for emulsion morphologies. Briefly, electrical conductivities were measured for top/bottom, and bottom/top phases that form the sides of the tie triangle diagram by mixing measured volumes of the pre-equilibrated phases.

The set-up of the morphology measurement system is shown in Figures 1 and 2. Only a brief description of the measurement system and the experimental procedures involved is provided below. More details can be obtained elsewhere [5,17-23]. A typical experiment involves gravimetrical preparation of a mixture of the amphiphile, hydrocarbon, and brine; equilibration of the mixture in a large, thermostated buret until phase separation is complete (at least 48 hours); and careful separation of the layers. A Princeton Applied Research Model 124A lock-in amplifier and a radiometer conductivity cell with platinized electrodes are used to measure the conductances. Emulsion volume fractions will be changed by additions from a buret of one of the conjugate phases to the sample, which is contained in a jacketed, thermostated beaker. The sample will be mixed throughly by continuous magnetic stirring and circulation through a pump. The conductivity of the emulsions will be measured 5 minutes after each phase addition. The measurement frequency will 
be $2 \mathrm{kHz}$, at which electrode polarization effects will be negligible for conductivities smaller than $100 \mathrm{mS} . \mathrm{cm}^{-1}$. The temperature can be controlled within $0.1^{\circ} \mathrm{C}$ by a Lauda M2 thermostat bath.

Electrical conductivities were measured for pre-equilibrated top and bottom phases of the mixtures formed with various volume fractions of ethanol $(2,10,20,33,43,50,56$, and $60 \%)$, keeping the volumes of ethylbenzene and water the same in each mixture. Also electrical conductivities were measured for top/bottom, and bottom/top emulsions that form the sides of the tie triangle diagram by mixing measured volumes of the pre-equilibrated phases.

Following the conductivity measurements, conductivity data were predicted employing a theoretical model based on Maxwell equations [5] developed in this project.

\section{$\underline{\text { Surtek Measurements }}$}

Core flooding measurements were conducted by our industrial partner, Surtek, CO, to characterize condensate recovery.

Linear corefloods were performed to determine the amount of hydrocarbon recovery. $2 \%$ surfactant (ethanol) dissolved in $10 \mathrm{mM} \mathrm{NaCl}$ water was injected into into brine and ethylbenzene saturated core (Figure 3). The porous media was Berea sandstone. Ethanol solutions were injected at different injection rates to define fluid rheology as the ability of the solution to flow through porous media. Ethylbenzene recovery was determined by a mass balance and by modified Dean-Stark extraction of the core after the displacement studies. Effluent sample was analyzed for ethylbenzene recovery potential.

Radial corefloods were conducted to estimate the additional amount of hydrocarbon production due to the injection of surfactant solution into core in the radial direction (Figure 4). Ethanol prior to and after $10 \mathrm{mM} \mathrm{NaCl}$ water injection was flowed through the Berea sandstone. Ethylbenzene recovery was determined by a mass balance and by modified Dean-Stark extraction of the core after the displacement studies. Effluent sample was analyzed for ethylbenzene recovery potential. 


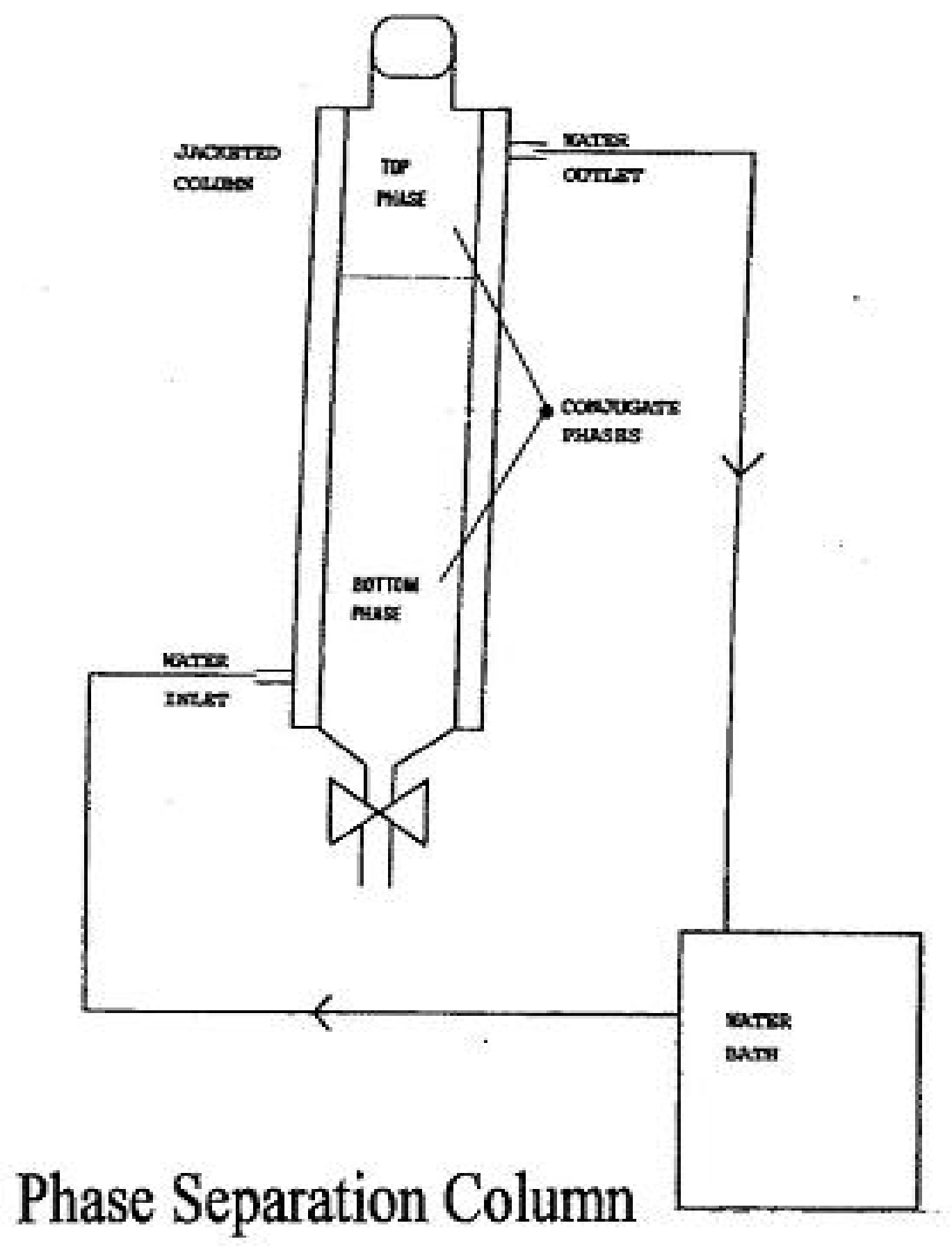

Figure 1. Preparation of the Top, and Bottom Phases 


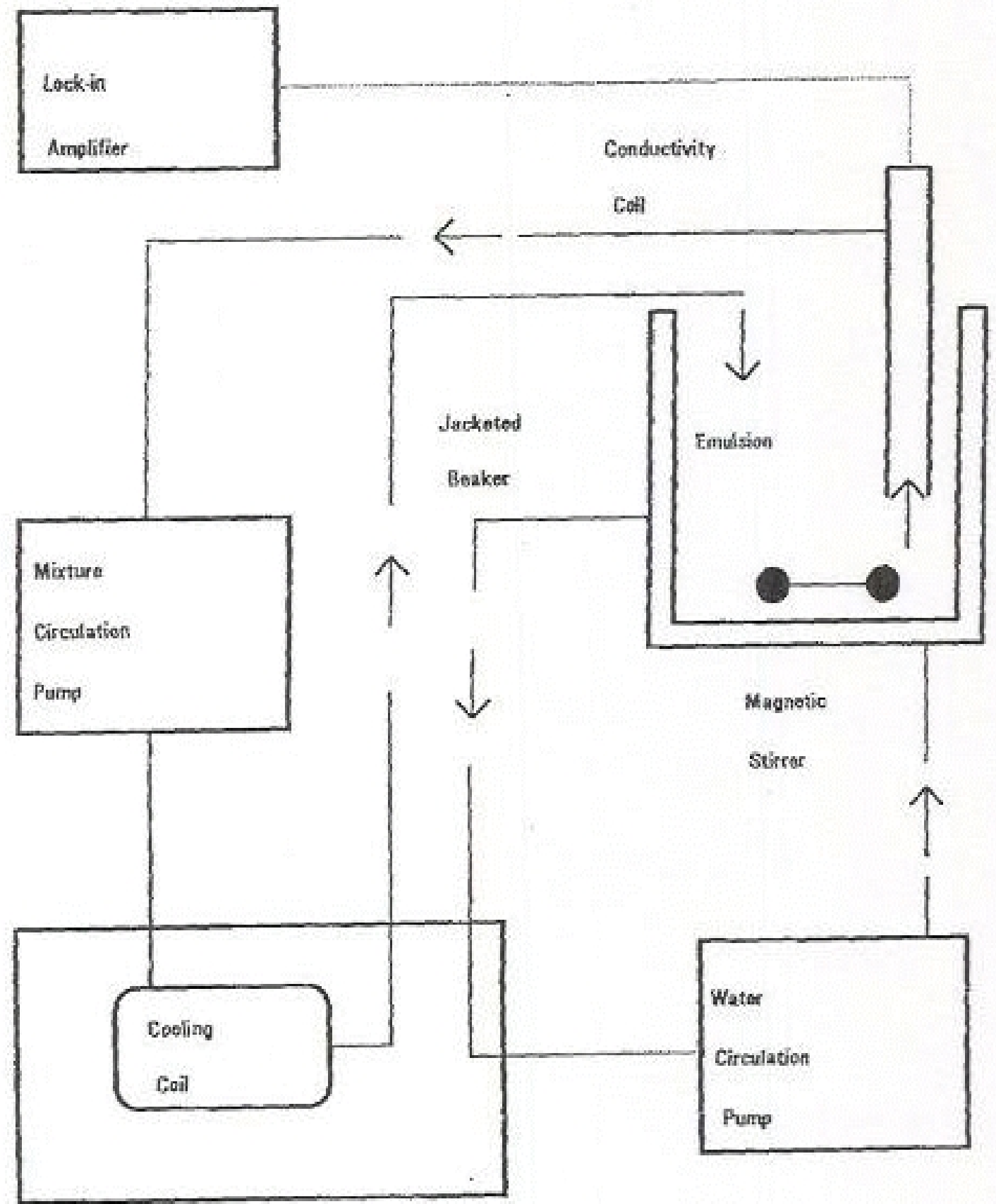

Water Bath

Experimental Apparatus.

Figure 2. Conductivity Measurement System 


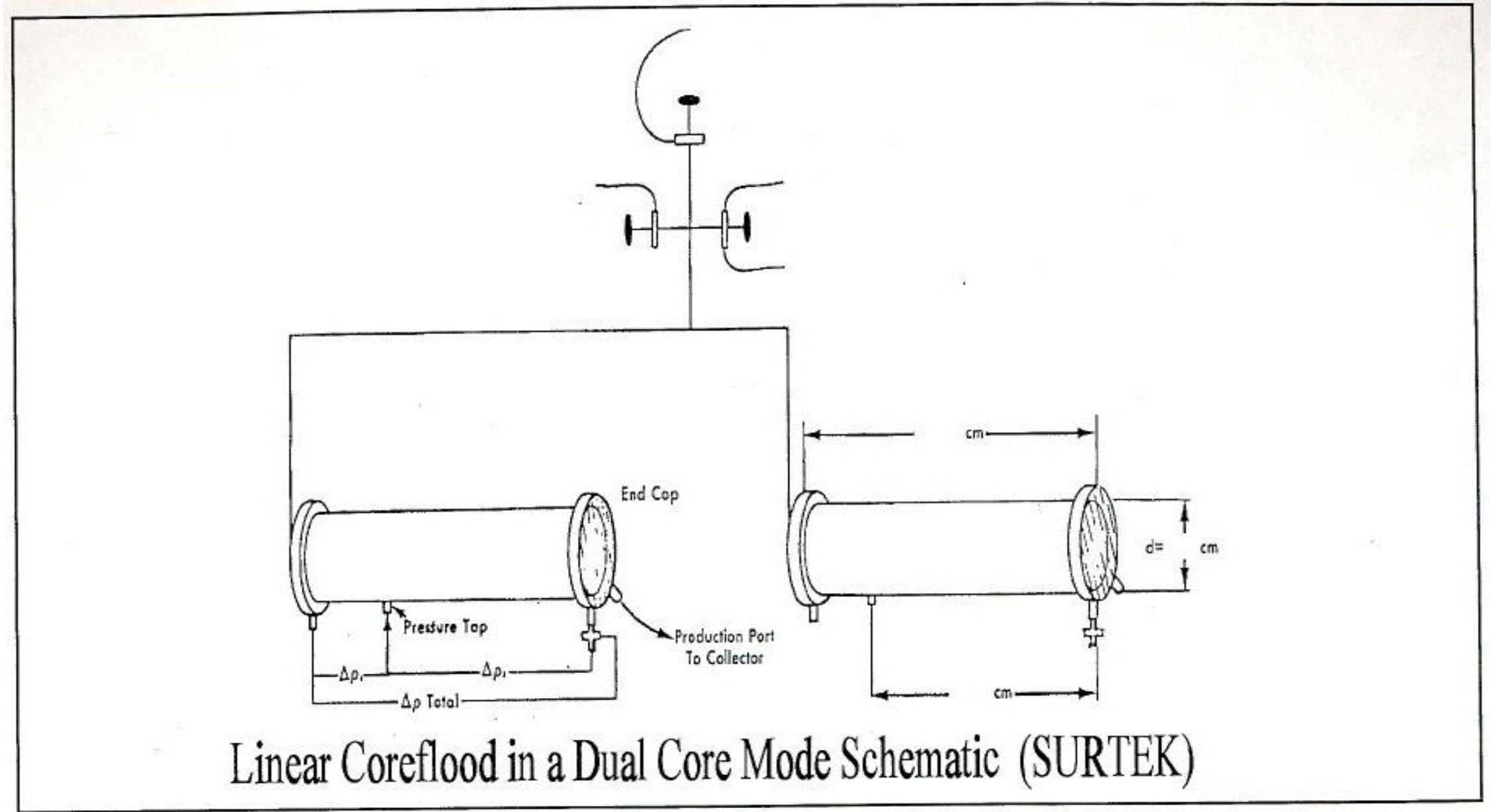

Figure 3. Linear Coreflood Measurement System 


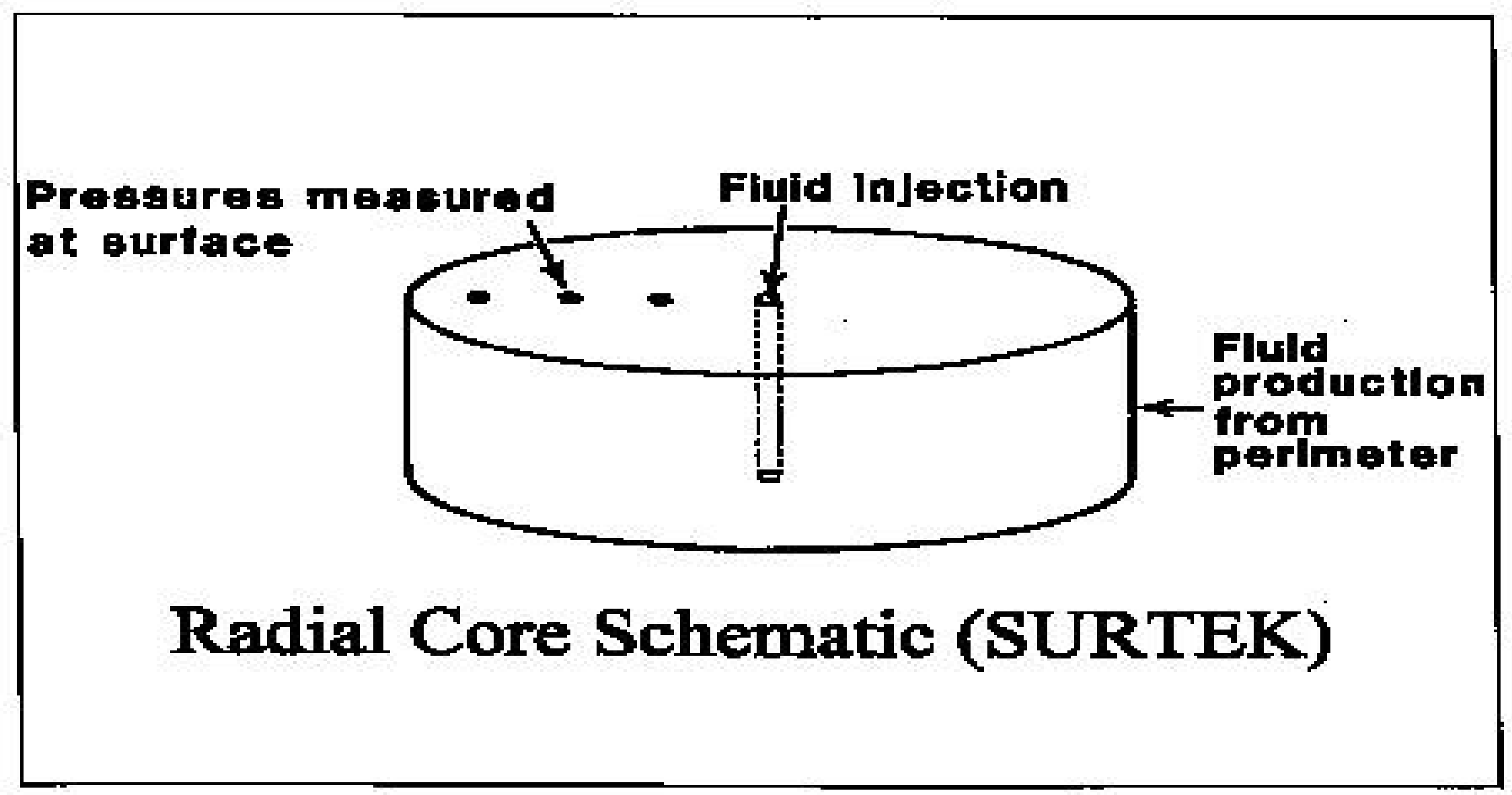

Figure 4. Radial Coreflood Measurement System 

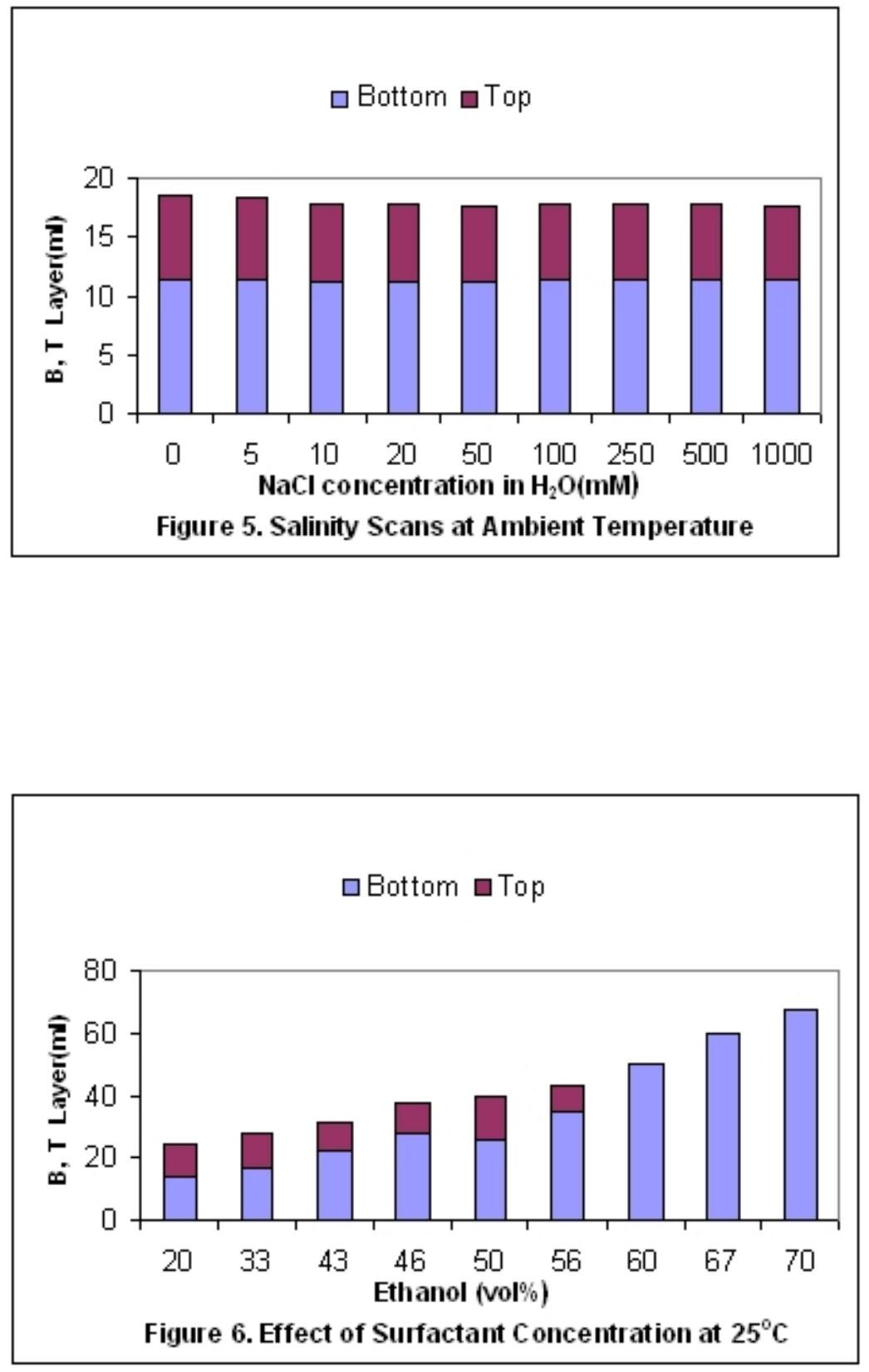

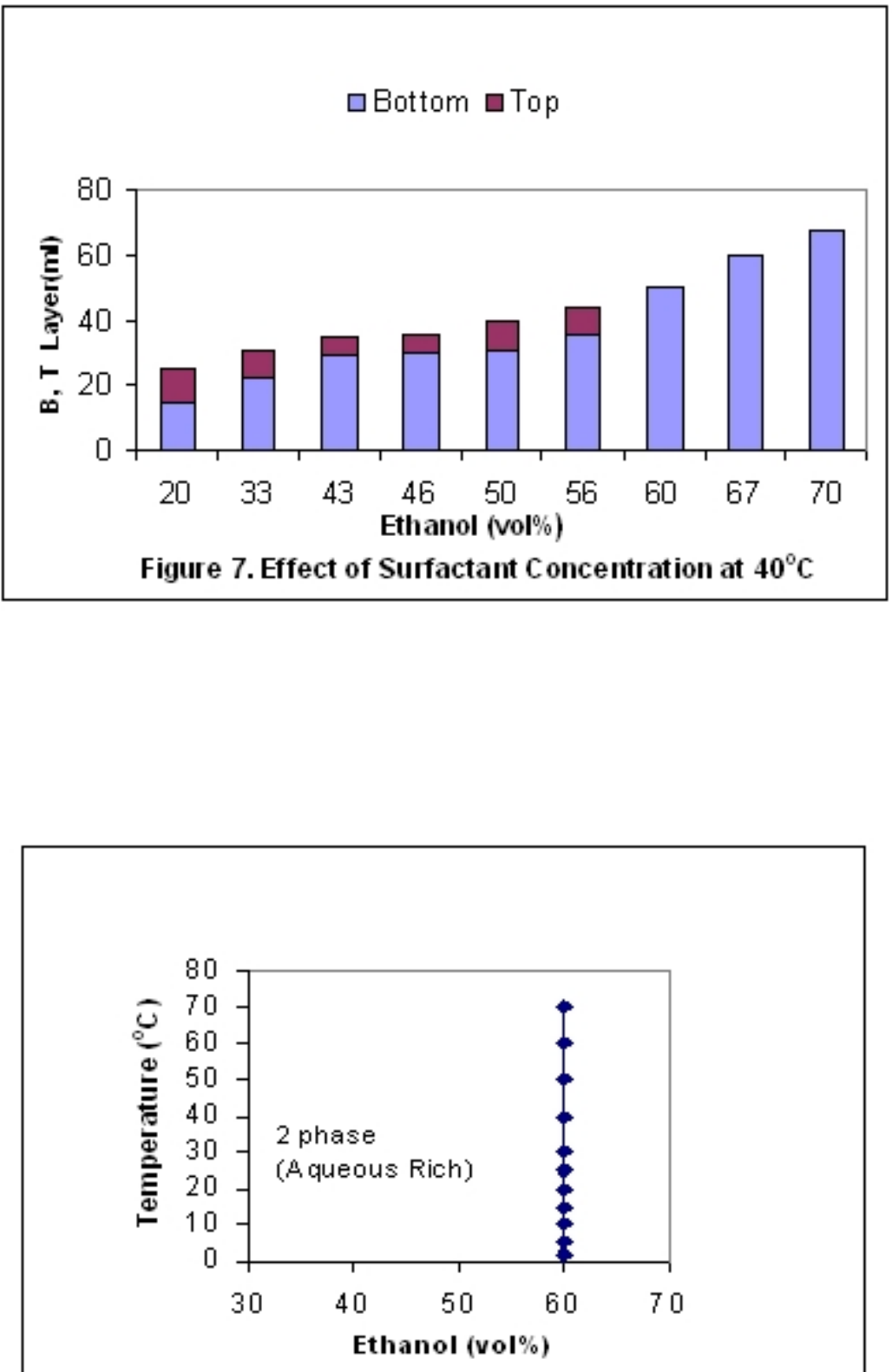

Figure 8. Temperature-Composition Cross Section of the Two Phas e Region in the Ethylbenzene/Water Ethanol System 


\title{
RESULTS AND DISCUSSIONS
}

\author{
$\underline{\text { Morehouse Results }}$
}

Figure 5 presents the results of the salinity scans that were conducted at room temperature. It can be seen that the mixture produces only two phases and incremental saline concentration does not make significant changes in the volume or number of the phases produced. Ross et al. [24] conducted phase studies for benzene-ethanol-water at $20^{\circ} \mathrm{C}$ and observed two phases. Salinity scans were repeated at $30^{\circ} \mathrm{C}$ and observed salinity has no effect at higher temperatures as well.

Figures 6 and 7 present the results of the temperature scans at room temperature and at 40 ${ }^{\circ} \mathrm{C}$. It can be seen that only two phases formed up to $60 \mathrm{vol} \%$ of the surfactant. It was also observed that the aqueous phase was more in volume than the condensate rich top phase. Experiments were repeated from 2 to $70{ }^{\circ} \mathrm{C}$. Figure 8 presents the results of the temperature scans from 2 to $70{ }^{\circ} \mathrm{C}$. It can be seen that above $60 \mathrm{vol} \%$ of the surfactant, the mixture produces single phase for the range of temperatures tested. It is concluded that the temperature range tested here is invariant to this chemical system and produces more aqueous bottom phase than the condensate rich top phase.

Following the set-up of the emulsion measurement system, the electronic instruments and data acquisition modules involved were tested for proper operation of the system. Then, the conductivity output was normalized with that obtained for $10 \mathrm{mM} \mathrm{NaCl}$ water. Electrical conductivities were measured for top and bottom phases of the ethylbenzene/water/ethanol system. Conductivity of the top phase was found small and remained almost the same for variations in ethanol volume fraction of the mixture. Conductivities were also measured for emulsions formed by mixing measured volumes of the top phase into a fixed volume of the bottom phase and vice versa at room temperature. Electrical conductivity of the emulsion decreased as the fraction of volume of the top phase was increased and vice versa. More experiments in smaller incremental volume of the conjugate phase into the emulsion were performed and the inversion phenomena where the discontinuous phase becomes continuous phase and vice versa was observed. These experiments were then repeated for top/bottom and bottom/top conjugate pair phases obtained by mixing various ethanol concentrations $(2,10,20,33,43,50,56$, and $60 \mathrm{vol} \%)$ while keeping the volumes of ethylbenzene and water the same in each

Modeling efforts that were established in previous studies [5,17-23] to predict electrical conductivities and inversion phenomena were reviewed. A theoretical model to predict the conductivity measurements using Maxwell equations [5] was developed in this study. Electrical conductivity measurements were then compared with the predictions of the conductivity model. Results of the comparisons for 2, 10,33, and 56\% ethanol volume in the mixture are presented in Figures 9-12. As can be seen, a good agreement was obtained between the predicted emulsion conductivities and the measured values. This provides considerable confidence that the morphology assignments are correct. 


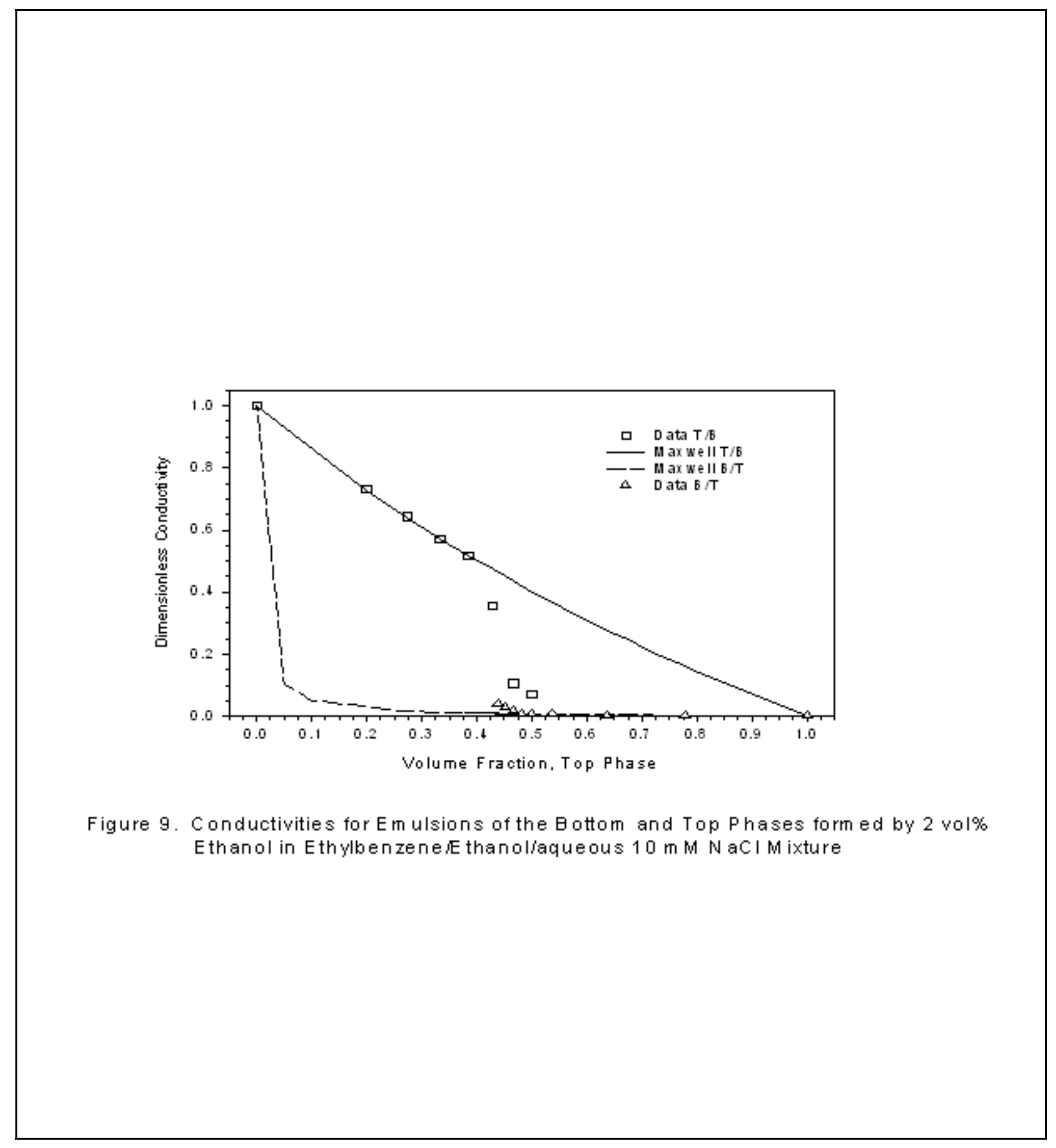




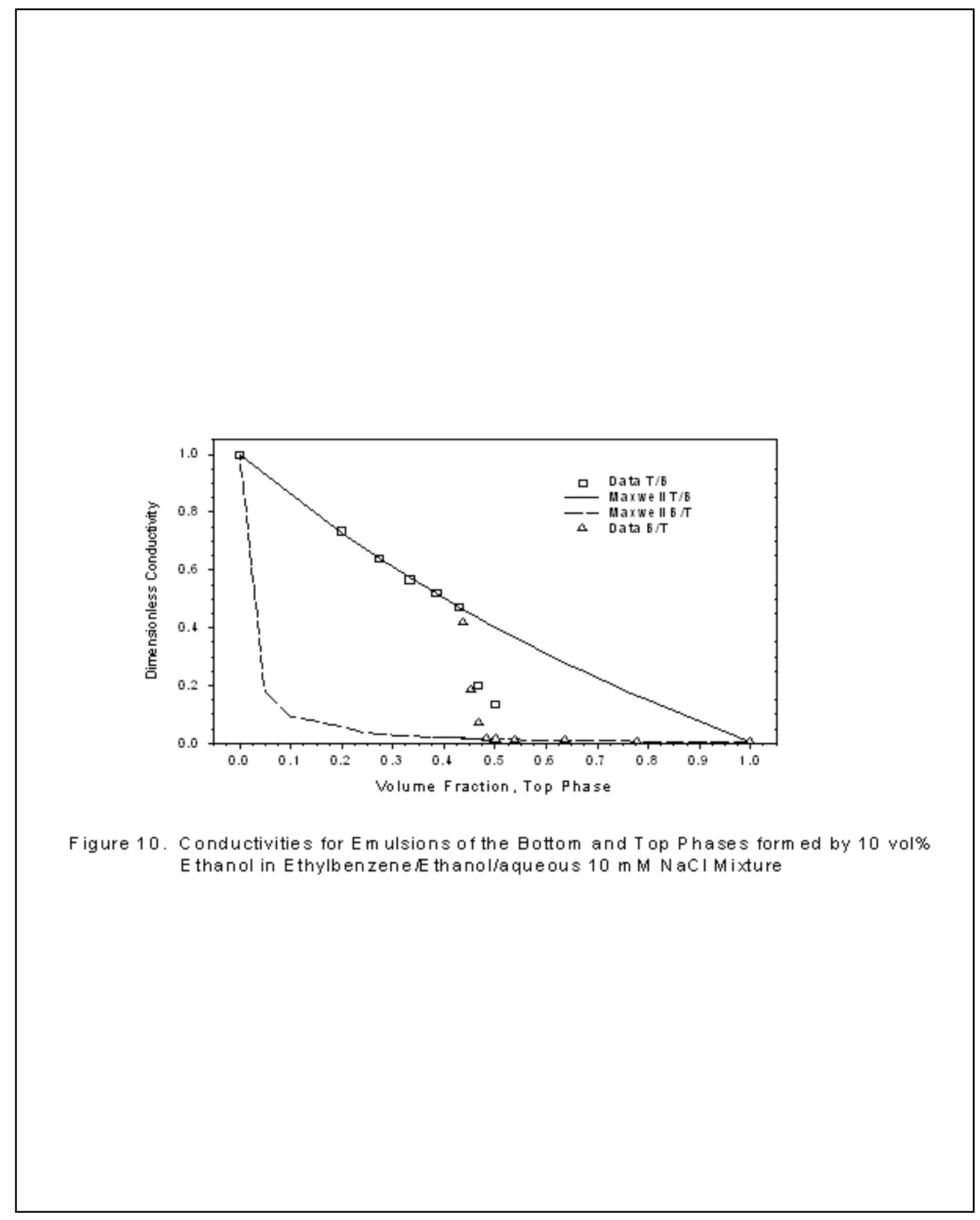




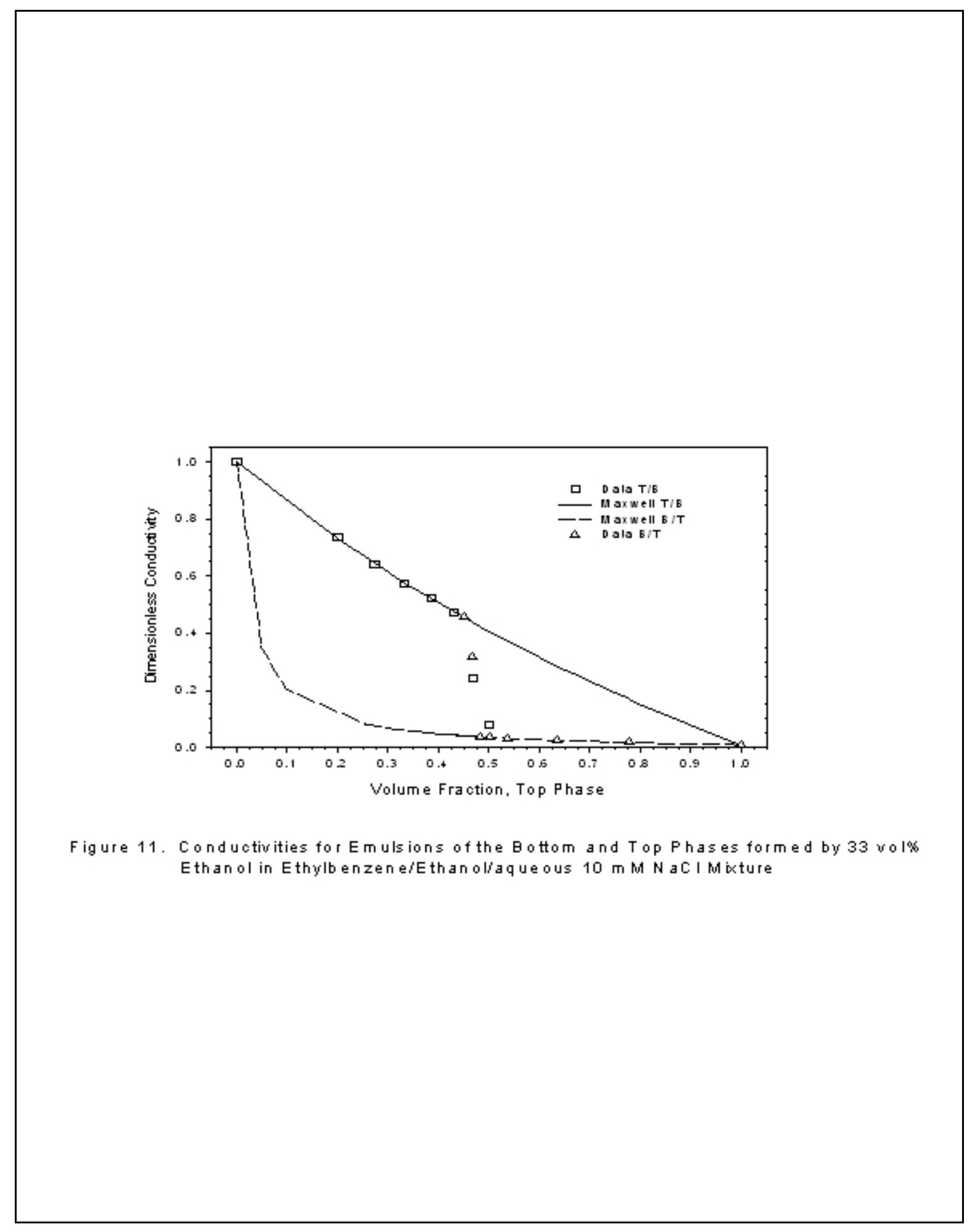




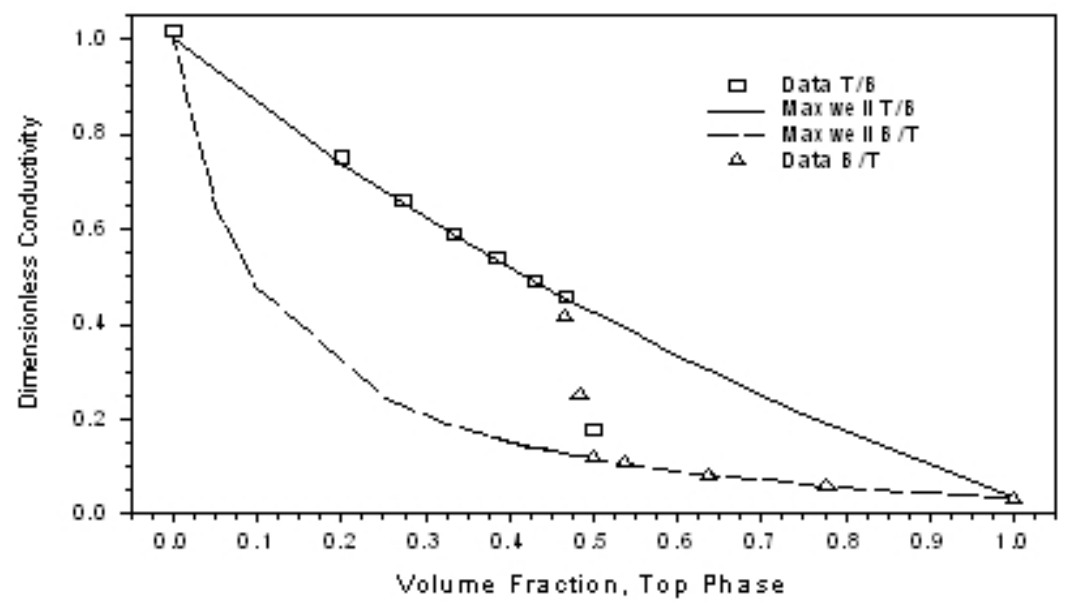

Figure 12. Conductivities for $E \mathrm{~m}$ ulsions of the Bottom and Top Phases form ed by 56 vol\% Ethanol in Ethylbenzene $\mathbb{E}$ thanoliaque ous $10 \mathrm{~m} \mathrm{M} \mathrm{NaCI} \mathrm{M}$ ixture 


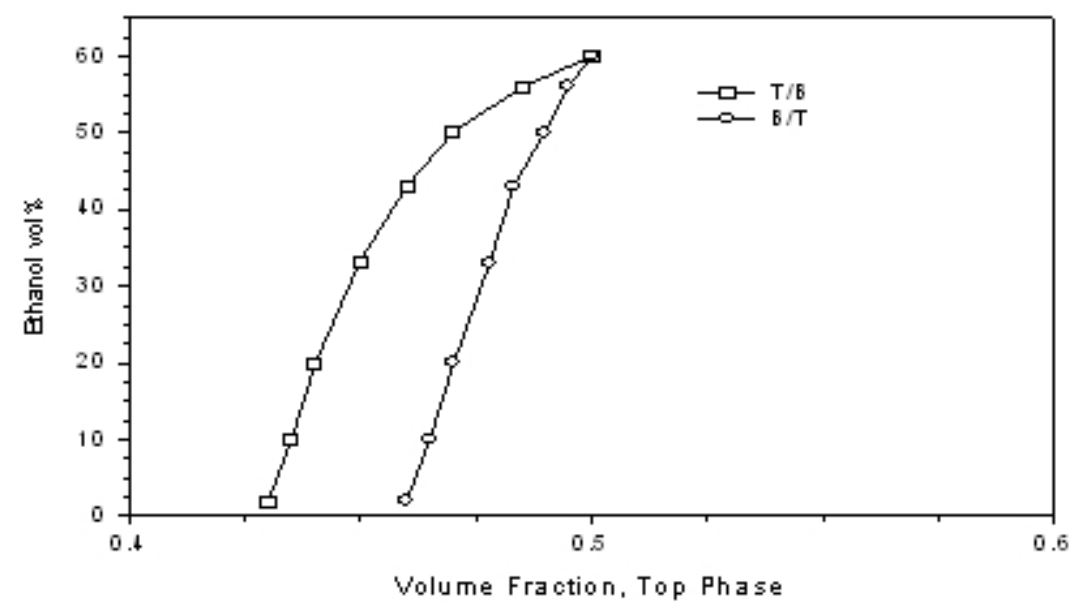

Figure 13. Hysteresis lines between $T / B$ and $B / T$ inversions of the system E thylbenzeneiE thanoliaque ous $10 \mathrm{~m} \mathrm{M} \mathrm{NaCl}$ 
Table 1: Ethanol volume\% in the mixture and Volume Fractions of Inversions

\begin{tabular}{|l|l|l|l|}
\hline Ethanol Vol\% & $\mathbf{Q}_{\mathbf{T} / \mathbf{B} \text { - } / \mathbf{T}}$ & $\mathbf{Q}_{\mathbf{B} / \mathbf{T}-\mathbf{T} / \mathbf{B}}$ & $\Delta$ \\
\hline 2 & 0.43 & 0.46 & 0.03 \\
\hline 10 & 0.435 & 0.465 & 0.03 \\
\hline 20 & 0.44 & 0.47 & 0.03 \\
\hline 33 & 0.45 & 0.478 & 0.028 \\
\hline 43 & 0.46 & 0.483 & 0.023 \\
\hline 50 & 0.47 & 0.49 & 0.02 \\
\hline 56 & 0.485 & 0.495 & 0.01 \\
\hline 60 & 0.5 & 0.5 & 0.00 \\
\hline
\end{tabular}


The ethanol concentrations and phase volume fractions $(\mathrm{Q})$ at which inversions were found are summarized in Table 1. These data are plotted in Figure 13, along with a critical end point $\left(\mathrm{Q}_{\mathrm{c}}\right.$ $=0.5$, Ethanol concentration $=60 \mathrm{vol} \%)$. The inversion hysteresis lines of Figure 13 closely resembles to the previously postulated (phase volume-temperature) dispersion morphology diagram [4,18-19]; i.e., the T/B and B/T inversion hysteresis lines in phase volume-surfactant concentration space meet at a critical point that coincided with a critical end point for the phases.

\section{$\underline{\text { Surtek Results }}$}

Surtek, our industrial partner in this project, conducted a detailed analysis of the data obtained in their coreflooding measurements.

Results of the linear coreflooding experiment coducted by Surtek are as follows: A total of $30.8 \%$ of the original ethylbenzene saturation was recovered by injection of a $10 \mathrm{mM} \mathrm{NaCl}$ solution. Injection of a 16 pore volume of $2 \%$ ethanol dissolved in $10 \mathrm{mM} \mathrm{NaCl}$ did not improve ethyl benzene recovery. Radial coreflooding experiments were then conducted at Surtek. This time surfactant flooding was carried out with a $100 \%$ ethanol solution prior to the water flooding to assess the effectiveness of the surfactant in ethylbenzene recovery.

Results of the radial coreflooding experiments conduced by Surtek are as follows: In Run 1, $10 \mathrm{mM} \mathrm{NaCl}$ without ethanol injection recovered $31.5 \%$ of the initial ethyl benzene saturation. Injection of ethanol following $10 \mathrm{mM} \mathrm{NaCl}$ produced a tertiary ethyl benzene bank with maximum ethyl benzene cuts of $32 \%$. Only two phases were produced. It should be noted that the number of phases obtained by Surtek agrees with the phase work studied by Morehouse. Ross et al. [24] conducted phase studies for a similar mixture, benzene-ethanol-water, at $20{ }^{\circ} \mathrm{C}$ and observed two phases.

In Run 2, 50 vol\% of pure (100\%) ethanol was injected and flowed through the Berea sandstone after Ethyl Benzene Saturation. $69 \%$ of the initial ethyl benzene was recovered. The results of this radial coreflood is very encouraging. While $50 \mathrm{vol} \%$ of ethanol injection does not make economic sense when injecting a large fraction of a pore volume, injection of sufficient volume to remove water and condensate from around the near well bore area of a gas well could be economic. By removing the water and condensate from around the well bore, relative permeability to gas will increase permitting gas production rate to increase. This could be a temporary affect and may have to be repeated to keep gas rates up. However, it is no different than stimulation and re-stimulation of an oil well. Key is how often this must be done.

\section{Outcome to-date}

The project has supported two undergraduate students (Kwame Donkoh, Hersey McCulloch) from Morehouse College, and one graduate student (Gautam Saha) from Georgia State University. Gautam Saha has completed his graduate school requirements. 
Several experiments and theoretical analyses were conducted in this project and the experimental results were compared with predictions. These activities resulted in several reports, and conference presentations and are listed below.

1. Sampath, R., Dixon, R., Moeti, L., and McCulloch, H., Investigation of Phase and Emulsion Behavior, Surfactant Retention, and Condensate Recovery for Condensate/Water/Ethanol Mixtures, UCR/HBCU/OMI Annual Contractor Review Meeting sponsored by NETL/DOE, June 3-4, 2003, Pittsburgh, PA

2. Sampath, R., Dixon, R., Moeti, L., and McCulloch, H., Investigation of Phase and Emulsion Behavior, Surfactant Retention, and Condensate Recovery for Condensate/Water/Ethanol Mixtures, Spring Seminar Series, Department of Physics and Dual Degree Engineering, Morehouse College, Atlanta, GA, April 2004.

3. Sampath, R., Dixon, R., Moeti, L., and McCulloch, H., Salinity and Temperature Scans for Condensate/Water/Ethanol Mixtures, SPE/DOE Fourteenth Symposium on Improved Oil Recovery, April 20, 2004, Tulsa, OK.

4. Sampath, R., Dixon, R., and Moeti, L., Investigation of Phase and Emulsion Behavior, Surfactant Retention, and Condensate Recovery for Condensate/Water/Ethanol Mixtures, First Semi-Annual Progress Report submitted to NETL/DOE, Pittsburgh, April 2003.

5. Sampath, R., Dixon, R., and Moeti, L., Investigation of Phase and Emulsion Behavior, Surfactant Retention, and Condensate Recovery for Condensate/Water/Ethanol Mixtures, Second Semi-Annual Progress Report submitted to NETL/DOE, Pittsburgh, October 2003.

6. Sampath, R., Dixon, R., and Moeti, L., Investigation of Phase and Emulsion Behavior, Surfactant Retention, and Condensate Recovery for Condensate/Water/Ethanol Mixtures, Third Semi-Annual Progress Report submitted to NETL/DOE, Pittsburgh, April 2004.

7. Sampath, R., Dixon, R., and Moeti, L., Investigation of Phase and Emulsion Behavior, Surfactant Retention, and Condensate Recovery for Condensate/Water/Ethanol Mixtures, Fourth Semi-Annual Progress Report submitted to NETL/DOE, Pittsburgh, October 2004.

8. Sampath, R., Brown, C. S., and Moeti, L., Investigation of Phase and Emulsion Behavior, Surfactant Retention, and Condensate Recovery for Condensate/Water/Ethanol Mixtures, Fifth Semi-Annual Progress Report submitted to NETL/DOE, Pittsburgh, April 2005.

9. Sampath, R., Brown, C. S., and Moeti, L., Investigation of Phase and Emulsion Behavior, Surfactant Retention, and Condensate Recovery for Condensate/Water/Ethanol Mixtures, Sixth Semi-Annual Progress Report submitted to NETL/DOE, Pittsburgh, October 2005. 


\section{CONCLUSION}

This project sought to characterize phase and emulsion behavior, and condensate recovery for condensate/water/ethanol systems. Ethylbenzene that has the equivalent carbon number was used as the model condensate. Salinity scans were performed for various salt concentrations to identify the optimal salinity and salinity intervals in which all phases coexisted. It was found that only two phases formed, and salinity has no significant effect in the volumes of the phases formed. Measurements were made with $10 \mathrm{mM} \mathrm{NaCl}$ water for surfactant concentrations from 2 to 70 volume percent at room temperature. It was found that only two phases were formed upto $60 \mathrm{vol} \%$ concentration of the surfactant. The mixture produced only a single phase above $60 \mathrm{vol} \%$ of surfactant. Emulsion morphology data in the form of electrical conductivity measurements were obtained for bottom/top, and top/bottom conjugate pair phases of the ethylbenzene/water/ethanol system. Electrical conductivity of the bottom phase decreased as ethanol volume fraction of the mixture increased. Conductivity of the top phase was found small and remained almost the same for variations in ethanol volume fraction in the mixture. Also inversion phenomena was observed. Prediction of the conductivity data obtained was conducted employing Maxwell equations. A good agreement was obtained between the predicted emulsion conductivities and the measured values. Work was also conducted at Surtek, Golden, CO, our industrial partner in this project, to measure the effectiveness for condensate recovery employing radial coreflooding technique. $50 \mathrm{vol} \%$ of pure $(100 \%)$ ethanol was injected and flowed through the Berea sandstone after Ethyl Benzene Saturation. Only two phases were produced and $69 \%$ of the initial ethyl benzene was recovered.

\section{ACKNOWLEDGMENTS}

This work is supported under FETC/DOE Grant No. DE-FG26-02NT15447. Technical discussions provided by Dr. Duane Smith of National Energy Technology Laboratory, Morgantown, and Mr. Jesse Garcia of National Energy Technology Laboratory, Tulsa, Oklahoma are gratefully acknowledged.

\section{REFERENCES}

1. Duane H. Smith and K.-H. Lim, "Morphology and Inversions of Two Fluids in Systems of Three and Four Thermodynamic Dimension," J. Phys. Chem. 94, 3746-52 (1990).

2. Kunieda, H. and Friberg, S. E., Bull. Chem. Soc. Jpn. 1981, 54, 1010.

3. Duane H. Smith, "The Role of Critical Points in HLB and the Phase Inversion Temperature, Evidence from the Cyclohexane/ Water/ i-C9H19C6H4 (OCH2CH2)9.2OH--Temperature Trigonal Prismatic Diagram," J. Colloid Interface Sci. 108, 471 (1985). 
4. Duane H. Smith, "Comparison of Emulsions with the Phase Diagrams of the Systems in which They Form" in Microemulsions, H.L. Rosano and M. Clausse, Eds. (Marcel Dekker, New York, 1987).

5. Duane H. Smith, Ramanathan Sampath, and Dady B. Dadyburjor, "Temperature-Dependent Inversion Hysteresis Lines for Emulsions of Middle and Bottom Phases of the System C6H13(OC2H4)2OH/n-Tetradecane/'Water'," J. Phys. Chem. 100, 17558-62 (1996).

6. Becher, P., J. Soc. Cosmetic Chem. 1958, 9, 141.

7. Duane H. Smith and K.-H. Lim, "An Experimental Test of Catastrophe and Critical-Scaling Theories of Emulsion Inversion," Langmuir 6, 1071 (1990).

8. $\quad$ Ross, S. and Kornbrekke, R. E., J. Colloid Interface Sci. 1981, 81, 58.

9. K.-H. Lim and Duane H. Smith, "Experimental Test of Catastrophe Theory in Polar Coordinates: Emulsion Inversion for the Ethanol/Benzene/ Water System," J. Colloid Interface Sci. 142, 278-90 (1991).

10. Duane H. Smith, G. L. Covatch, and K.-H. Lim, "Morphologies and Inversions of Emulsions of Conjugate Microemulsion and Oleic Phases in an Amphiphile/oil/Water System between Its Critical Endpoint Temperatures," Langmuir 7, 1585 (1991).

11. Clark, S.R., Pitts, M.J. and Smith, S.M.: "Design and Application of an AlkalineSurfactant-Polymer Recovery System to the West Kiehl Field," (1993), SPE Advanced Technology Series, Vol 1, pages 172-179.

12. Manji, K.H. and Stasiuk, B.W.: "Design Considerations for Dome's David Alkali/Polymer Flood," Can. J. Pet. Tech., (May-June 1988), Vol. 27, pages 49-54.

13. Pitts, M.J., Surkalo, H. and Wyatt, K.: "Design and Field Implementation of Alkaline-Surfactant-Polymer Chemical Enhanced Oil Recovery Systems," proceedings of the 1995 UNITAR International Conference on Heavy Crude and Tar Sands, Houston, TX, Feb 12-16, 1995.

14. Lin, F.J., Besserer, G.J., and Pitts, M.J.: "Laboratory Evaluation of Cross-linked Polymer and Alkaline-Surfactant-Polymer Flood," (1987), Can. J. Pet. Tech., Vol. 35 (Nov.-Dec.).

15. Earlougher, R.C. Jr., O'Neal, J.E., and Surkalo, H.: Micellar Solution Flooding: Field Test Results and Process Improvements," SPE 5337, presented at the Rocky Mountain Regional Meeting, April 7-9, 1975. 
16. Davis, J.A., Jr. and Jones, S.C.: "Displacement Mechanisms of Micellar Solutions," J. Pet. Tech., (Feb 1973), pages 186-194: Trans AIME, vol 243.

17. Sampath, R., Moeti, L., Smith, D., and Pitts, M., Characterization of Surfactants for Enhanced Oil Recovery, Technology Transfer Session, Historically Black Colleges/Universities and Other Minority Institutions Annual Symposium, April 28-29, 1998, Ocean City, MD.

18. Chen, J., Sampath, R., Moeti, L., and Smith, D., Salinity and Temperature Scans for a Novel AEC Surfactant, Technology Transfer Session, Historically Black Colleges/Universities and Other Minority Institutions Seventh Annual Symposium, April 1999, Miami, FL.

19. Chen, J., Sampath, R., Moeti, L., and Smith, D., Investigation of Phase and Emulsion Behavior for Novel Alcohol Ethoxycarboxylate Surfactants, Technology Transfer Session, Historically Black Colleges/Universities and Other Minority Institutions Annual Symposium, April 28-29, 1998, Ocean City, MD.

20. Johnson, G. K., A Study of Three-Phase Emulsion Behavior, PhD Dissertation, 1993, West Virginia University, Morgantown.

21. Duane H. Smith, G. K. Johnson, and D. Dadyburjor, "Continuous Phases in Emulsions of Three Liquids," Langmuir 9, 2089-92 (1993).

22. G. K. Johnson, D. Dadyburjor, and Duane H. Smith, "Electrical Conductivities of ThreePhase Emulsions. Part 2," Langmuir 10, 2523-27 (1994).

23. Duane H. Smith, G. K. Johnson, Y. C. Wang, and K.-H. Lim, "Electrical Conductivities of Three-Phase Emulsions. Part 1," Langmuir 10, 2516-22 (1994).

24. Sydney Ross, and Ralph E. Kornbrekke, "Change of Morphology of a Liquid-Liquid Dispersion as a Stochastic Process", J. of Colloid and Interface Science, vol. 81, No. 1, 1981. 